University of Windsor

Scholarship at UWindsor

$11-18-2002$

\title{
Development of form and function in peripheral auditory structures of the zebrafish (Danio rerio)
}

Dennis M. Higgs

University of Windsor

Audrey K. Rollo

Marcy J. Souza

Arthur N. Popper

Follow this and additional works at: https://scholar.uwindsor.ca/biologypub

Part of the Biology Commons

\section{Recommended Citation}

Higgs, Dennis M.; Rollo, Audrey K.; Souza, Marcy J.; and Popper, Arthur N., "Development of form and function in peripheral auditory structures of the zebrafish (Danio rerio)" (2002). Journal of the Acoustical Society of America, 2, 113, 1145-1154.

https://scholar.uwindsor.ca/biologypub/96

This Article is brought to you for free and open access by the Department of Biological Sciences at Scholarship at UWindsor. It has been accepted for inclusion in Biological Sciences Publications by an authorized administrator of Scholarship at UWindsor. For more information, please contact scholarship@uwindsor.ca. 


\title{
Development of form and function in peripheral auditory structures of the zebrafish (Danio rerio) ${ }^{\text {a) }}$
}

\author{
Dennis M. Higgs, ${ }^{\text {b) }}$ Audrey K. Rollo, Marcy J. Souza, ${ }^{\mathrm{c})}$ and Arthur N. Popper \\ Department of Biology, University of Maryland, College Park, Maryland 20742
}

(Received 10 May 2002; revised 3 November 2002; accepted 18 November 2002)

\begin{abstract}
Investigations of the development of auditory form and function have, with a few exceptions, thus far been largely restricted to birds and mammals, making it difficult to postulate evolutionary hypotheses. Teleost fishes represent useful models for developmental investigations of the auditory system due to their often extensive period of posthatching development and the diversity of auditory specializations in this group. Using the auditory brainstem response and morphological techniques we investigated the development of auditory form and function in zebrafish (Danio rerio) ranging in size from 10 to $45 \mathrm{~mm}$ total length. We found no difference in auditory sensitivity, response latency, or response amplitude with development, but we did find an expansion of maximum detectable frequency from $200 \mathrm{~Hz}$ at $10 \mathrm{~mm}$ to $4000 \mathrm{~Hz}$ at $45 \mathrm{~mm}$ TL. The expansion of frequency range coincided with the development of Weberian ossicles in zebrafish, suggesting that changes in hearing ability in this species are driven more by development of auxiliary specializations than by the ear itself. We propose a model for the development of zebrafish hearing wherein the Weberian ossicles gradually increase the range of frequencies available to the inner ear, much as middle ear development increases frequency range in mammals. () 2003 Acoustical Society of America. [DOI: $10.1121 / 1.1536185]$
\end{abstract}

PACS numbers: 43.80.Lb, 43.64.Ri, 43.64.Tk [WA]

\section{INTRODUCTION}

A comparative approach to studies of auditory processing can be informative both for questions of human hearing deficits and for questions of auditory evolution. This is particularly true from a developmental perspective, as even small changes in auditory structure can have profound effects on hearing ability (Werner and Gray, 1998). Most of the work done thus far on development of hearing structure and function (reviewed in Werner and Gray, 1998) has been in mammals (e.g., Ehret and Romand, 1981; Walsh et al., 1986a; Geal-Dor et al., 1993; Hill et al., 1998) and a few species of birds (e.g., Gray and Rubel, 1985; Dmitrieva and Gottlieb, 1992; Gray, 1993; Brittan-Powell and Dooling, 2000), with less attention paid to other vertebrates. These studies have shown that as mammals and birds develop, responses are found first to low and middle frequencies and only later do responses to higher frequencies develop (e.g., Moore and Irvine, 1979; Ehret and Romand, 1981; Gray and Rubel, 1985; Brittan-Powell and Dooling, 2000), despite the fact that morphological development proceeds from high frequency to low frequency regions of the cochlea (Pujol and Marty, 1970; Rubel, 1978). In mammals this apparent discrepancy has been linked to the opening of the external ear canal (Hill et al., 1998) and formation of the middle ear bones (Ehret and Romand, 1981; Geal-Dor et al., 1993), both of which are necessary to transmit higher frequency

\footnotetext{
${ }^{a)}$ Portions of this work were presented at the annual meeting of the Association for Research in Otolaryngology, 2001.

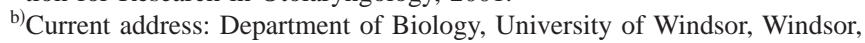
ON N9B 3P4, Canada. Electronic mail: dhiggs@uwindsor.ca

${ }^{c)}$ Current address: North Carolina State University, College of Veterinary Medicine, Raleigh, NC.
}

information to the inner ear. Mammals and birds also show a developmental decrease in the latency of brainstem response to auditory stimulation (e.g., Walsh et al., 1986b; Kuse and Okaniwa, 1993; Hill et al., 1998; Brittan-Powell and Dooling, 2000) and a developmental increase in amplitude of brainstem response (e.g., Walsh et al., 1986c; Kuse and Okaniwa, 1993; Brittan-Powell and Dooling, 2000), perhaps due to changes in myelination of neurons in the auditory system, innervation of the sensory cells of the ear, and cochlear mechanics (Walsh et al., 1986b, c). Thus, correlation between development of auditory performance and structure can be used to construct hypotheses on the role of different portions of the auditory system in hearing ability. The ability to test evolutionary hypotheses is constrained, however, by the relatively limited focus on birds or mammals of previous studies.

Apart from a few studies during metamorphosis of frogs (e.g., Schofner and Feng, 1981; Boatwright-Horowitz and Megala Simmons, 1995, 1997) the only other developmental studies of auditory function of which we are aware are a few done in fishes. In the ray (Raja clavata), there is an increase in the sensitivity of the ramus neglectus nerve, stimulated as an isolated ear preparation, with development, and it has been suggested that this increased sensitivity is due to an increase in the number of sensory hair cells (Corwin, 1983). In contrast, no change in auditory sensitivity with growth has been found in the juvenile and adult stages of goldfish (Carassius auratus) using heart rate conditioning (Popper, 1971) and zebrafish (Danio rerio) using evoked brainstem responses (Higgs et al., 2002a) despite significant increases in the number of sensory hair cells (Platt, 1977; Higgs et al., 2002a). In other teleosts there are either large increases in auditory sensitivity over the entire range of detectable fre- 
quencies [using behavioral conditioning, damselfish, Pomacentrus spp. (Kenyon, 1996)] or small improvements in sensitivity over a much narrower range of audible frequencies [Red Sea bream, Pagrus major, with heart rate conditioning (Iwashita et al., 1999); gourami, Trichopsis vittata, with brainstem responses (Wysocki and Ladich, 2001)] during the juvenile and adult stages. Behavioral work has shown increases in responsiveness to a broadband auditory stimulus during the larval and juvenile periods of fish [Atlantic herring, Clupea harengus (Blaxter and Batty, 1985); red drum, Sciaenops ocellatus (Fuiman et al., 1999)] and in herring this increased responsiveness has been correlated to inflation of the auditory bullae, gas-filled chambers directly connected to the inner ear in this species (Blaxter and Batty, 1985).

The purpose of the current study was to examine developmental changes in auditory structure and function in zebrafish. Zebrafish are an important model species for many aspects of vertebrate biology and are particularly useful for auditory work because they belong to the superorder Ostariophysi, a group of fish known as hearing specialists due to their broad range of detectable frequencies and specialized Weberian apparatus connecting the swim bladder to the ear (von Frisch, 1938; Fay and Popper, 1974). While there has been some examination of the morphology of the adult (Platt, 1993) and developing (Waterman and Bell, 1984; Haddon and Lewis, 1996; Riley et al., 1997; Bang et al., 2001) zebrafish ear, there has been no examination of the development of zebrafish auditory function except for our previous work on hearing in juveniles and adults (Higgs et al., 2002a).

\section{MATERIALS AND METHODS}

\section{A. Animal supply}

We examined auditory abilities and morphological development in zebrafish from 10 to $45 \mathrm{~mm}$ total length (TL). The zebrafish used in this study were bred and reared in our fish colony at the University of Maryland. Adults used as broodstock were purchased from a local pet store, kept in a $38 \mathrm{~L}$ aquarium over marbles, and fed several times each day. Embryos were collected by siphoning from the bottom of the tank. Larvae were reared in small net baskets in a $38 \mathrm{~L}$ aquarium until they reached approximately $15 \mathrm{~mm}$ total length TL, at which point they were placed loose into a tank and kept in uncrowded conditions (see Higgs et al., 2002a). Ages of fish used were not determined because length is a better indicator of developmental state than age for fish (Fuiman et al., 1998; Higgs et al., 2002a). All animal rearing and experimental methods were approved by the Institutional Animal Use and Care Committee at the University of Maryland.

\section{B. Auditory physiology}

We used the auditory brainstem response (ABR) to examine changes in hearing ability during the larval, juvenile, and adult period of zebrafish to ascertain how hearing function may change in this species. The use of ABR has become common in studies of auditory ability in a wide variety of vertebrates (e.g., Corwin et al., 1982; Klein, 1984; Walsh et al., 1986a; Brittan-Powell and Dooling, 2000), including fishes (e.g., Corwin et al., 1982; Kenyon et al., 1998; Yan and Curtsinger, 2000; Higgs et al., 2002a), and is particularly suited to developmental investigations as it requires no training of the animal and can be performed noninvasively. This last attribute was essential for success in our very small zebrafish larvae. The methods used to measure auditory abilities in the current study are similar to those in Higgs et al. (2002a) but the animals were considerably smaller in the current study.

A total of 31 zebrafish from 10 to $45 \mathrm{~mm}$ TL were used for $\mathrm{ABR}$, with all testing conducted in a sound attenuating chamber (Industrial Acoustics Company, New York). Animals were wrapped in a small mesh rectangle so that the entire fish was surrounded by mesh. The mesh was then clipped onto a holder and lowered into a $20 \mathrm{~L}$ water-filled bucket until the fish was completely submerged. This arrangement was loose enough to allow the fish to accelerate with the sound wave while remaining still enough for electrode placement. Fine positioning of the fish was controlled with a micromanipulator attached to the net holder. At final position the animal was approximately $25 \mathrm{~cm}$ above an underwater speaker (UW-30, Underwater Sound Inc., Oklahoma City, OK) and approximately $5 \mathrm{~cm}$ under the water surface. No muscle relaxants or anesthetics were needed for these experiments. Temperature of the water in the bucket ranged from $21^{\circ} \mathrm{C}$ to $23^{\circ} \mathrm{C}$. To control for possibly spurious responses, three dead adult fish were also tested in our apparatus. At no time did a dead fish give a "response" in any way similar to those seen for the experimental animals.

Presentation of auditory stimuli was controlled using a Tucker-Davis Technologies (TDT, Gainesville, FL) physiology apparatus controlled by a computer running SigGen and BioSig software (TDT). Stimuli were played from the computer to the UW-30 underwater speaker and consisted of tone bursts of 100, 200, 400,600, 800, 1000, 2000 or $4000 \mathrm{~Hz}$. No frequencies above $4000 \mathrm{~Hz}$ were presented because a previous study (Higgs et al., 2002a) showed that adult zebrafish never respond to higher frequencies. Calibration of output intensity for each frequency was accomplished using a hydrophone with precalibrated amplifier (calibration sensitivity of $-195 \mathrm{~dB}$ nominal $r e: 1 \mathrm{~V} / \mu \mathrm{Pa} ; 0.2-10 \mathrm{kHz}$, omnidirectional, InterOcean Systems, San Diego, CA). Use of this calibration technique revealed that our thresholds previously published for adult zebrafish (Higgs et al., 2002a) were in error (see erratum Higgs et al., 2002b) and results in thresholds approximately $30 \mathrm{~dB}$ lower than those used in the previous study. Tone bursts had a 5 -ms duration with a 2 -ms rise/fall time and were gated through a Hanning window. Despite large sidebands to the stimulus at frequencies below $800 \mathrm{~Hz}$, the level of the second harmonic was at least 15 $\mathrm{dBV}$ below the fundamental output frequency for all frequencies used.

Auditory responses to presented stimuli were collected using two stainless steel electrodes (Rochester ElectroMedical Inc., Tampa, FL) resting on the surface of the fish head. The recording electrode was positioned on the dorsal 
midline of the fish just posterior to the operculum using a micromanipulator. The reference electrode was placed, also using a micromanipulator, on the dorsal midline just behind the eyes. All exposed surfaces of the electrode tip that were not in direct contact with the fish were coated with fingernail polish for insulation. Care was taken not to penetrate the skin of the fish with the electrodes since this hampered survival. A total of 400 responses (200 from stimuli presented at 90 degrees and 200 from stimuli presented at 270 degrees to cancel stimulus artifacts) were averaged together for each sound level at each frequency, after going through a $60-\mathrm{Hz}$ notch filter to remove electrical noise.

Sound intensity at each frequency was increased in 5-dB steps until a stereotypical ABR was seen and then continued at least two steps $(10 \mathrm{~dB})$ higher to examine suprathreshold responses. Threshold was defined as the lowest level at which a clear response could be seen. This visual detection method is commonly employed in ABR studies (e.g., Walsh et al., 1986a; Hall, 1992) and gives identical results to those achieved using more statistical approaches (Mann et al., 2001).

For measurement of latency and amplitude of auditory responses we used responses that occurred at $5 \mathrm{~dB}$ above threshold for each animal examined above. A value of $5 \mathrm{~dB}$ above threshold was used to standardize across animals because of the variation between individuals in the level necessary for auditory stimulation. We did not use traces at a higher suprathreshold level because at some of the higher sound levels the responses were overwhelmed by stimulus artifact. Latency of the response was defined as the time between arrival of the stimulus (calculated as the time of stimulus onset minus $0.17 \mathrm{~ms}$ to account for travel time, assuming a speed of sound in water of $14872.6 \mathrm{~m} \cdot \mathrm{s}^{-1}$ and a travel distance of $25 \mathrm{~cm}$ ) and the maximum position of the first trough on the ABR waveform [Fig. 1(a)]. Amplitude was defined as the amplitude of the first trough relative to the background noise level just preceding the trough [Fig. 1(a)].

\section{Morphology}

To determine what morphological structures might be driving changes in auditory physiology we examined the number of saccular and lagenar sensory hair cells, the size of anterior and posterior regions of the saccule, the size of the swim bladder, and the development of Weberian ossicles in fish from 10 to $45 \mathrm{~mm}$ TL. Before fixation, fish were heavily anesthetized in MS-222 and the total length was measured. Fish were then fixed in $4 \%$ paraformaldehyde, except for those animals in which the swim bladder was measured. Swim bladders were removed for measurement from unfixed but anesthetized animals and immediately viewed under a dissecting microscope connected to a digital camera. The camera was connected to a computer with the MagnaFire (Optronics, Inc., Goleta, CA) imaging system. The lengths of the anterior and posterior chambers of the swim bladder were measured using NIH image software.

For hair cell counts, the saccules and lagenae of 12 fish from 15 to $45 \mathrm{~mm}$ TL were dissected free from the ear and stained with $2.5 \%$ Oregon-green conjugated phalloidin (Molecular Probes, Eugene, OR), an actin specific label that has been used to stain hair cell stereocilia in previous work (Higgs et al., 2002a). Whole mounts of stained epithelia were coverslipped with Prolong antifade (Molecular Probes) and viewed under a Zeiss epifluorescence microscope. Digital images were taken at $400 \times$ magnification across the surface of the epithelium and then compiled into one image reconstructing the entire epithelial surface using Photoshop 6.0 (Adobe Systems, Inc., San Jose, CA). Counts of the total hair cell number were then taken either directly from the computer screen or, more often, from printouts of these images.

Images of saccules stained with phalloidin were also used to measure saccule size. Images of entire saccular epithelia taken at $100 \times$ magnification were used in NIH image software to estimate the perimeter of both the anterior and posterior halves of the saccule for comparisons of differential growth of these two regions. Simple linear regression was used to examine changes in hair cell number and sizes of saccular regions with development. To compare growth rate of the two different saccular regions, the regression coefficients of saccular perimeter estimates (anterior versus posterior) were compared using the Student's $t$-test (Zar, 1984).

To estimate progression of Weberian ossicle development, eight animals from 5 to $20 \mathrm{~mm}$ TL were cleared and stained following the protocol of Dingerkus and Uhler (1977). Animals were fixed in 4\% paraformaldehyde, rinsed in distilled water for 2-3 days and, for larger animals, the skin was carefully removed to ensure penetration of the various chemicals. Animals were then placed in a mixture of alcian blue: $95 \%$ ethanol: glacial acetic acid for $24 \mathrm{~h}$, rinsed through an ethanol series into distilled water, and placed into a solution of aqueous sodium borate with trypsin until the flesh was cleared and the bones were visible as blue structures underneath (approximately 15-17 days). Cleared specimens were then placed in an aqueous $\mathrm{KOH}$ solution with approximately 2-4 grains of alizarin red for $24 \mathrm{~h}$ and transferred to glycerin for storage. Images of stained fish were captured under a Wild dissecting scope with imaging capabilities. Detailed description of Weberian development was not attempted as this work is near completion in a different laboratory (Grande and Young, submitted) and would therefore have represented a duplication of effort. Only enough animals were examined to provide a general picture of Weberian ossicle development.

\section{Statistical analyses}

Because of the difficulty of performing physiological recordings on the small animals measured in the current study, fish were grouped into size classes to perform statistical comparisons of functional development. Based on similarity of physiological responses, animals were grouped into size classes of $10-13 \mathrm{~mm}$ TL $(n=4), 15-16 \mathrm{~mm}$ TL $(n=3)$, 17-20 mm TL $(n=8)$, and animals over $20 \mathrm{~mm}$ TL $(n$ $=6$ ). As it was not possible to obtain measurements of fish TL before running an ABR due to stress of handling, it was not deemed efficient to continue running trials until each size class contained the exact same number of animals. Variability in responses was similar across size classes so we feel that more trials would have yielded the same results. For 

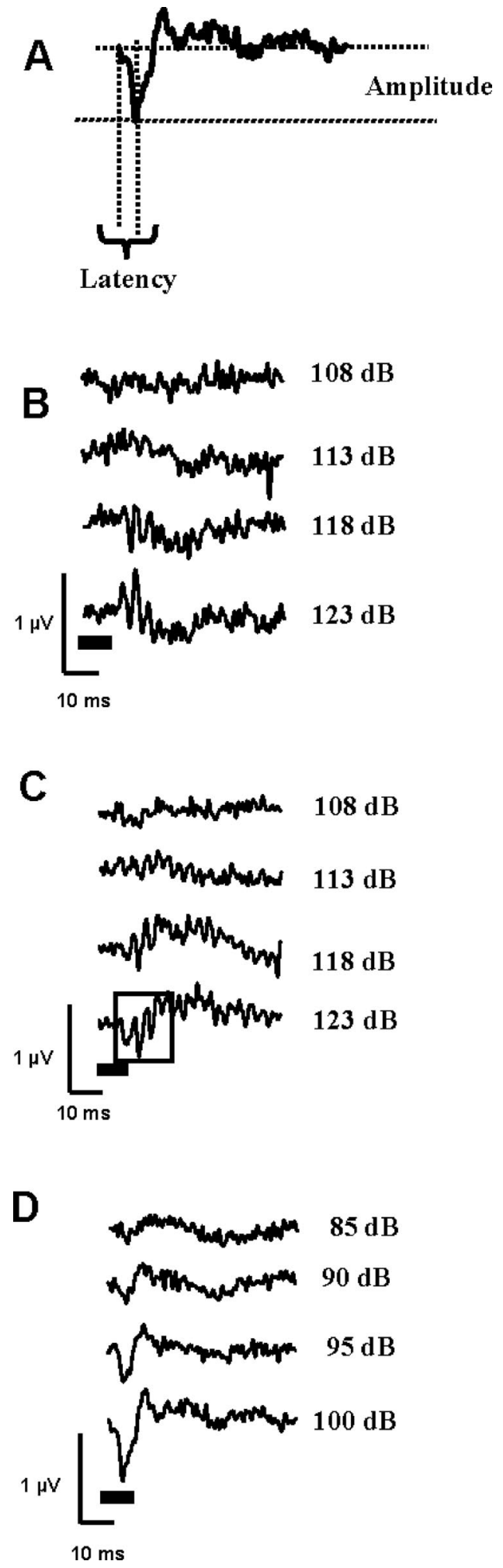

FIG. 1. (a) An example response waveform (to an $800-\mathrm{Hz}$ stimulus) showing measurement parameters for latency and amplitude of the response. There were no qualitative differences in the shape of ABR waveforms in response to $100-\mathrm{Hz}$ tone bursts across sizes, shown here for a $13.5-\mathrm{mm}$ total length zebrafish larva (b) and a 42-mm total length zebrafish larva (c). The box in (c) shows the waveform region containing the initial response with the apparent frequency doubling seen at 100 and $200 \mathrm{~Hz}$ for all fish tested. The ABR responses to $200-\mathrm{Hz}$ tone bursts looked identical to those shown here for $100 \mathrm{~Hz}$. Above $200 \mathrm{~Hz}$, all ABR waveforms looked like those shown here, for example, at $800 \mathrm{~Hz}$ in a 42-mm larva (d). All intensity values are $\mathrm{dB}$ re $1 \mu \mathrm{Pa}$. The bars under waveforms in (b)-(d) represent stimulus timing. Waveforms were band-pass filtered between 30 and 1000 $\mathrm{Hz}$ for presentation.

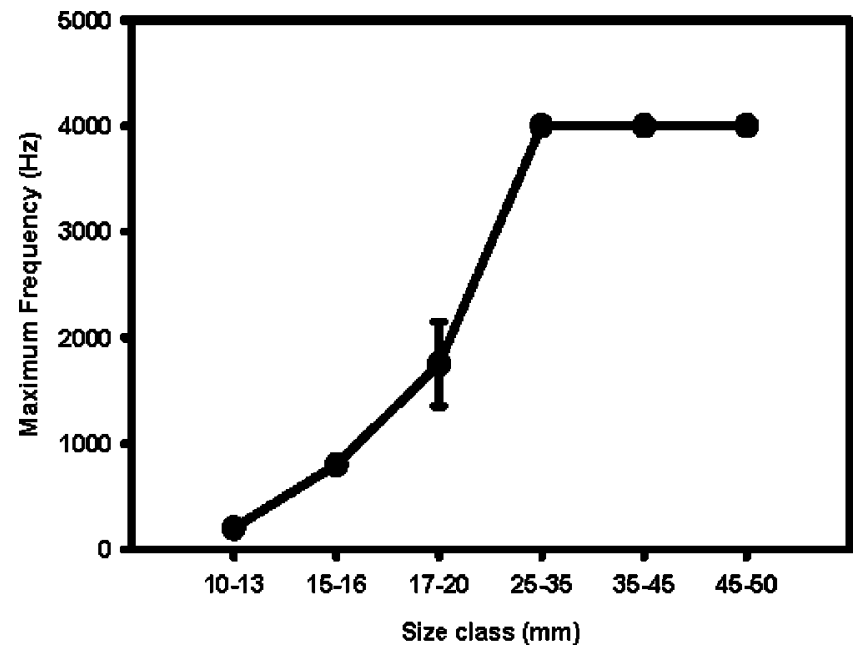

FIG. 2. The maximum frequency to which zebrafish showed an ABR gradually increased from $200 \mathrm{~Hz}$ in $10-13-\mathrm{mm}$ larvae up to $4000 \mathrm{~Hz}$ in larvae larger than $20 \mathrm{~mm}$. The $>20 \mathrm{~mm}$ size class has been subdivided to visually demonstrate that maximum frequency of detection plateaus at $4000 \mathrm{~Hz}$ for zebrafish. Symbols represent mean \pm 1 s.e. Numbers of animals used are given in text.

comparisons of threshold, latency, and amplitude of the response two-way ANOVAs were run with frequency and size class as the independent variables. When significant interactions of frequency*size class were found, individual ANOVAs were conducted across size class for each frequency to focus on the comparisons of interest, although this inflates the probability of a Type I error (Zar, 1984). Significance level for individual ANOVAs was therefore set to $\alpha / n-1$, where $n=8$ (the number of possible comparisons). This gives a critical $\alpha$ of 0.006 for individual frequency comparisons of threshold, latency, and amplitude. Morphological measures of hair cell number, saccule size and swimbladder size were conducted as simple linear regression, using $P$ $<0.05$ as the critical level.

\section{RESULTS}

\section{A. Physiology}

The shape of the ABR waveform differed depending on the frequency of the tone burst presented. For responses to $100-$ and $200-\mathrm{Hz}$ tone bursts, there were three waves within the first $15 \mathrm{~ms}$ of tone presentation with what appeared to be a frequency doubling response [Figs. 1(b) and (c)]. For tone bursts of $400 \mathrm{~Hz}$ and above, there was one large trough in response to the tone burst, with waveforms quickly returning to background levels after the response [Fig. 1(d)]. Within a given frequency, there was no apparent change in the shape of the waveforms over development in zebrafish [Figs. 1(b) and $(\mathrm{c})]$.

There was an increase in maximum frequency to which animals responded over development (Fig. 2). Animals from $10-13 \mathrm{~mm}(n=4)$ all responded to $100-$ and $200-\mathrm{Hz}$ tone bursts but never responded to any tone bursts above $200 \mathrm{~Hz}$. All animals from $15-16 \mathrm{~mm}(n=3)$ responded up to $800 \mathrm{~Hz}$ but never above. Animals from $17-20 \mathrm{~mm}(n=8)$ responded to tone bursts up to $2000 \mathrm{~Hz}$ with the mean maxi- 


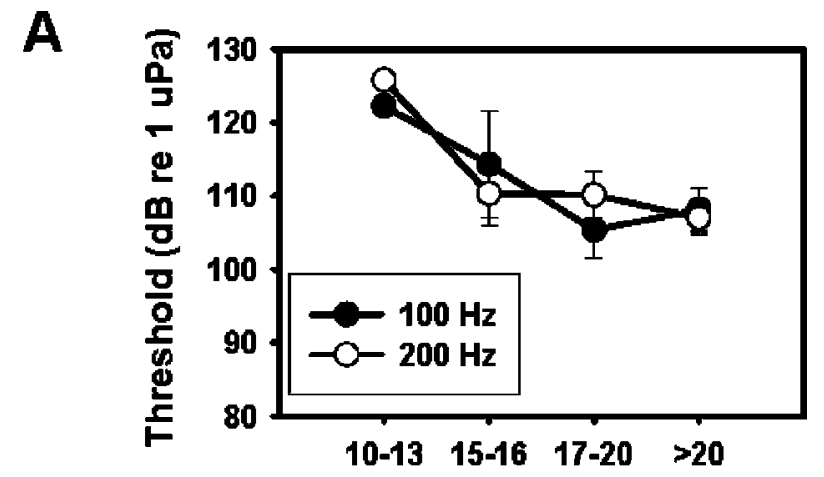

B
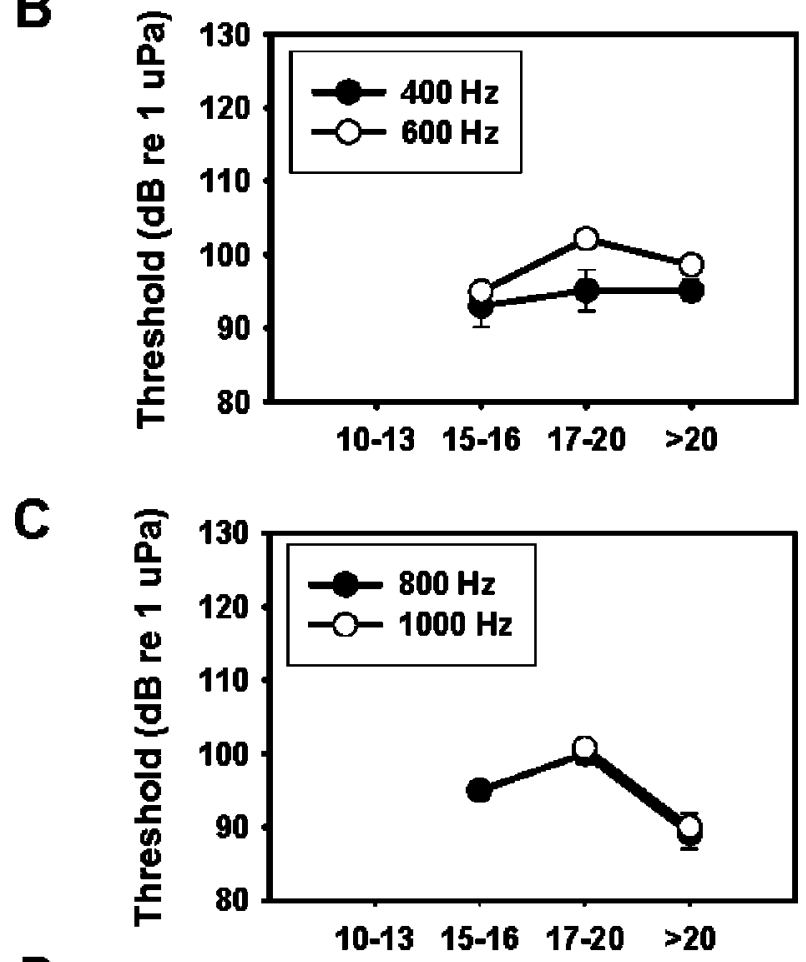

D

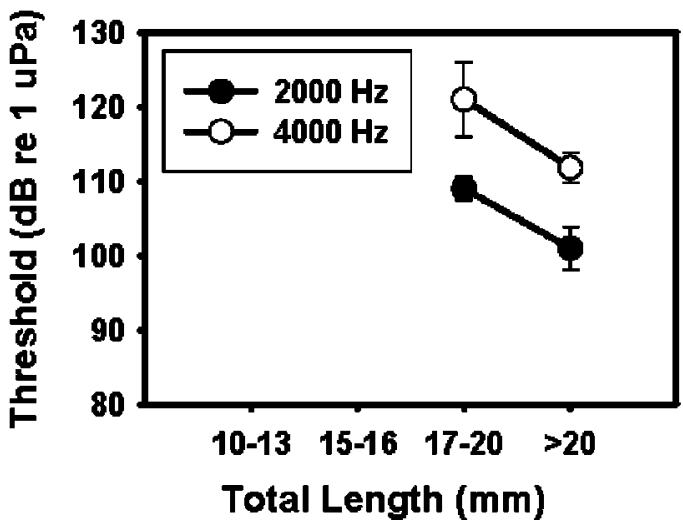

FIG. 3. Auditory threshold shows no consistent differences with growth of zebrafish larvae across frequencies. (a) 100 and $200 \mathrm{~Hz}$, (b) 400 and $600 \mathrm{~Hz}$, (c) 800 and $1000 \mathrm{~Hz}$, and (d) 2000 and $4000 \mathrm{~Hz}$.

mum frequency for the size class being $1750( \pm 399.5 \mathrm{SE})$ Hz. All animals larger than $20 \mathrm{~mm}(n=6)$ responded to tone bursts up to and including $4000 \mathrm{~Hz}$ (Fig. 2).

The threshold at which animals responded to specific frequencies showed no consistent changes with development (Fig. 3). While there was a significant frequency*size inter- action $(P<0.001)$ in the ANOVA for threshold, there were no consistent growth effects on threshold. At $100 \mathrm{~Hz}$ animals responded to tones between approximately 105 and $125 \mathrm{~dB}$ (re: $1 \mu \mathrm{Pa})$ with no significant differences $(P>0.05)$ between size classes [Fig. 3(a)]. At $200 \mathrm{~Hz}$ all animals responded between 105 and $125 \mathrm{~dB}($ re: $1 \mu \mathrm{Pa})$ with no consistent differences between size classes, although the smallest size class $(10-13 \mathrm{~mm})$ did tend to have higher thresholds than the three groups (15-16, 17-20, and $>20 \mathrm{~mm}$ ) of larger animals [Fig. 3(a)]. As frequency increased, fewer animals responded but there was no difference in threshold between sizes among fish that did respond [Figs. 3(b)-(d)]. At $800 \mathrm{~Hz}$, the best frequency of adult animals, threshold ranged from 90 to $100 \mathrm{~dB}$ ( re $1 \mu \mathrm{Pa}$ ) for all responding animals regardless of size [Fig. 3(c)].

There was a significant frequency*size interaction $(P$ $<0.001)$ in the ANOVA for latency but no frequencies showed a significant difference after adjusting for multiple comparisons (Fig. 4). The only frequencies over which all animals responded $(100$ and $200 \mathrm{~Hz})$ showed no significant differences $(P>0.05)$ in response latency over development [Fig. 4(a)]. There tended to be a higher latency of response to $100-$ and $200-\mathrm{Hz}$ tone bursts [overall mean latency $10-12$ ms, Fig. 4(a)] than to higher frequencies [overall mean latency 6-8.5 ms, Figs. 4(b)-(d)] but it is not clear if the responses at $100-200 \mathrm{~Hz}$ are comparable to those at higher frequencies (see below).

Within each frequency, there was no difference $(P>0.05)$ in response amplitude over development (Fig. 5). At 100 and $200 \mathrm{~Hz}$, the only frequencies at which all fish responded, all responses at $5 \mathrm{~dB}$ above threshold were between -0.3 and $-0.8 \mu \mathrm{V}$ with no consistent changes with size [Fig. 5(a)]. As frequency increased fewer size classes of fish responded to the stimulus, but, when fish did respond, the amplitude of the response was independent of fish size [Figs. 5(b)-(d)].

\section{B. Morphology}

There was a significant increase in the total number of saccular $\left(P<0.001, r^{2}=0.84\right)$ and lagenar $(P<0.001$, $\left.r^{2}=0.70\right)$ hair cells with development in zebrafish [Figs. 6(a) and (b)]. Saccular hair cell number increased from approximately 700 in the smallest animals examined (14 mm TL) up to 2000 in the largest fish [37 mm TL, Fig. 6(a)]. Lagenar hair cell number underwent a similar increase, from approximately 700 lagenar hair cells at $15 \mathrm{~mm}$ TL up to approximately 2500 at $36 \mathrm{~mm}$ TL and 3500 at $48 \mathrm{~mm}$ TL [Fig. 6(b)].

There was a significant increase in the perimeter of both the anterior $\left(r^{2}=0.49, P<0.01\right)$ and posterior $\left(r^{2}=0.79\right.$, $P<0.001$ ) regions of the saccule with development (Fig. 7). For both regions of the saccule, the perimeter of the sensory area went from approximately $0.5 \mathrm{~mm}$ at $14-15 \mathrm{~mm}$ TL to approximately $0.9 \mathrm{~mm}$ at $37 \mathrm{~mm}$ TL. There was no significant difference $(P>0.05)$ in the rate of increase of the perimeter between the anterior and posterior saccule (anterior: $Y=0.02 X+0.28$; posterior: $Y=0.02 X+0.10$ ), showing isometric growth of the two saccular regions relative to one another (Fig. 7). 
A

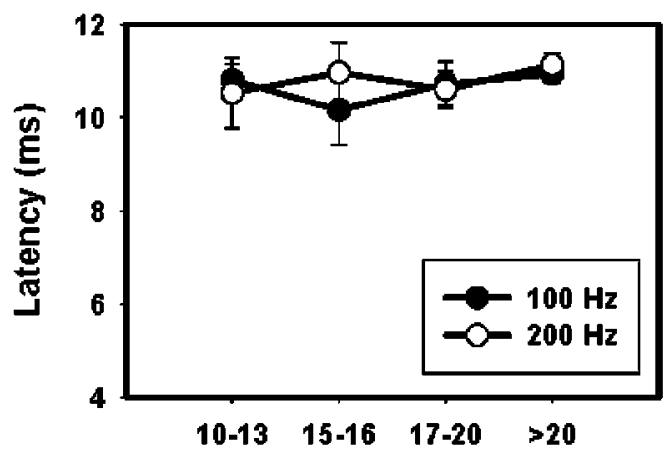

B

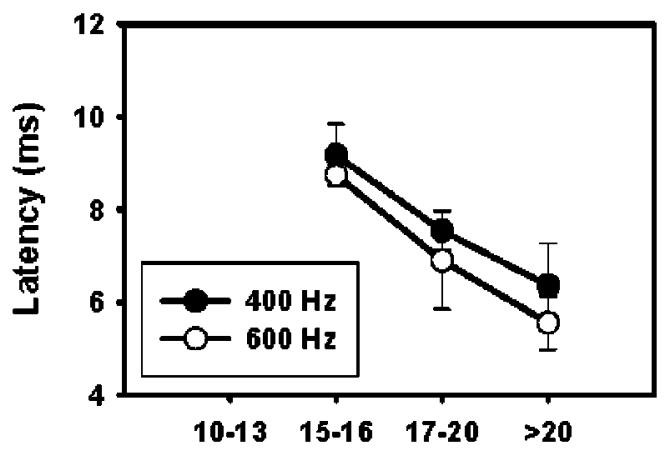

C

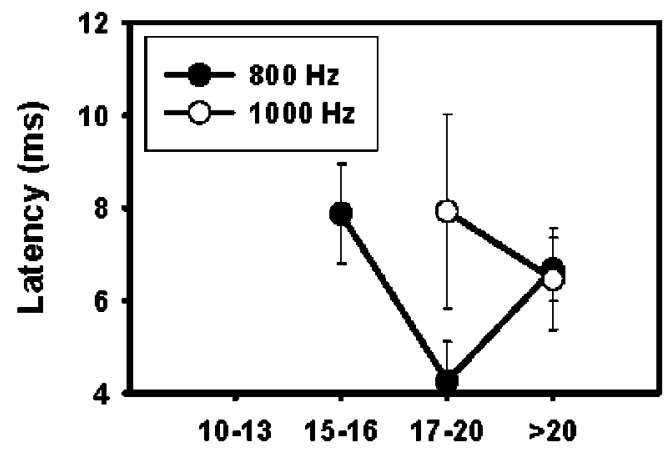

$\mathbf{D}$

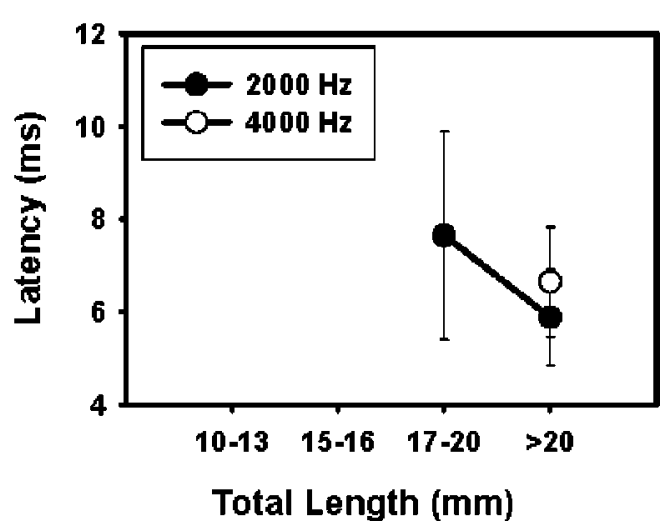

FIG. 4. The latency to response (time from arrival of stimulus to location of ABR trough) shows no consistent differences with growth of zebrafish larvae for the range of frequencies showing a response. (a) 100 and $200 \mathrm{~Hz}$, (b) 400 and $600 \mathrm{~Hz}$, (c) 800 and $1000 \mathrm{~Hz}$, and (d) 2000 and $4000 \mathrm{~Hz}$.
A

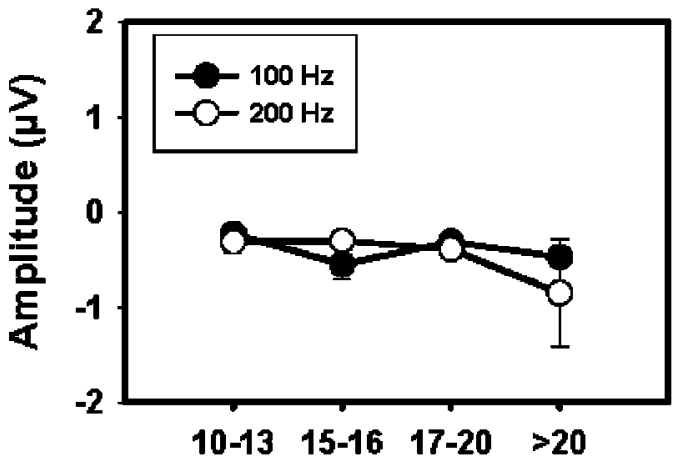

B
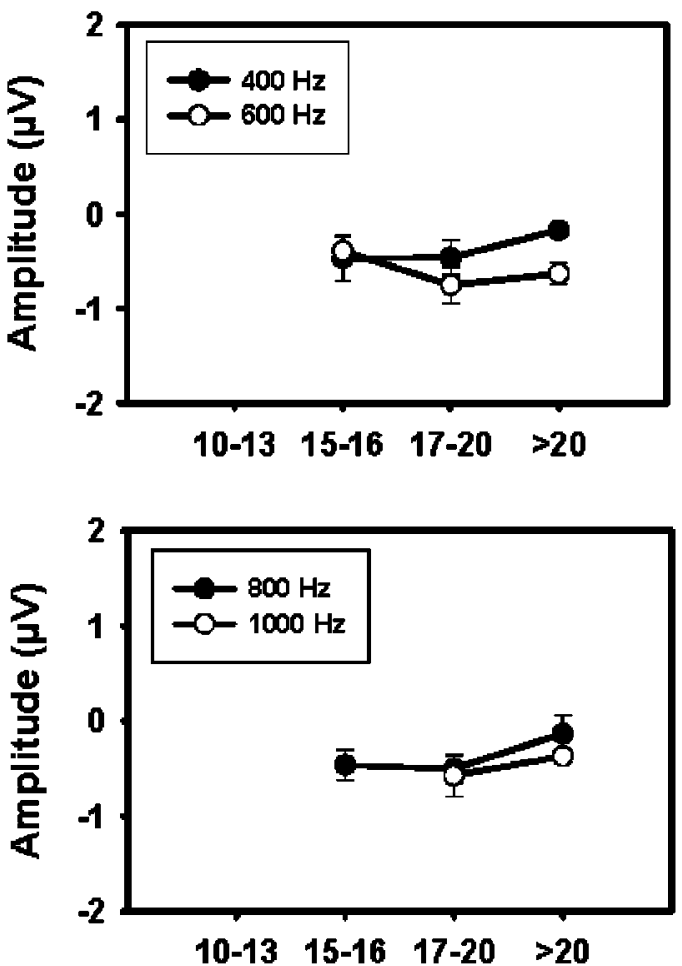

$\mathbf{D}$

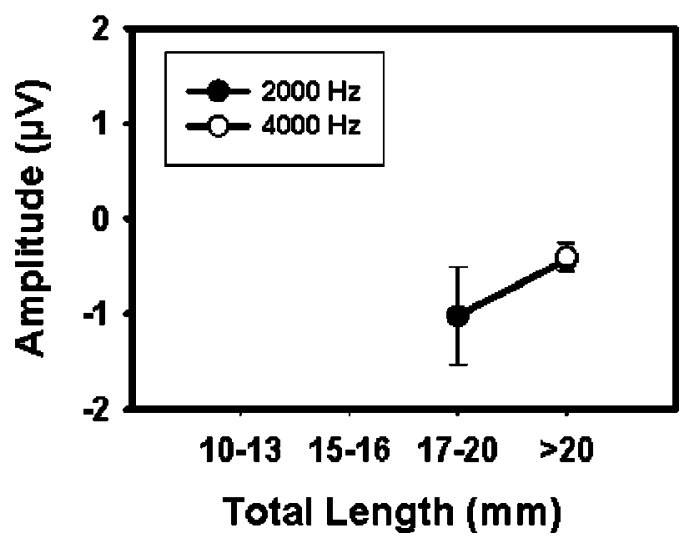

FIG. 5. The amplitude of the response (the size of the first trough relative to background noise levels) shows no consistent differences with growth of zebrafish larvae for the range of frequencies showing a response. (a) 100 and $200 \mathrm{~Hz}$, (b) 400 and $600 \mathrm{~Hz}$, (c) 800 and $1000 \mathrm{~Hz}$, and (d) 2000 and 4000 $\mathrm{Hz}$ 
A
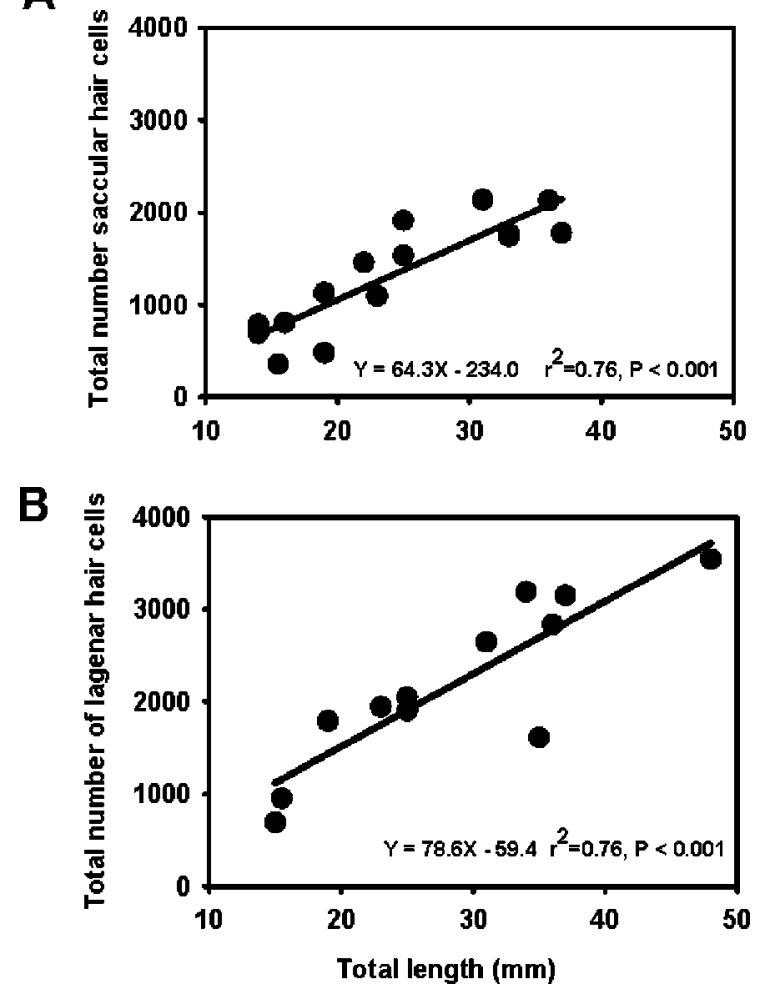

FIG. 6. There was a significant increase in the total number of saccular (a) and lagenar (b) sensory hair cells with growth of zebrafish.

The swim bladder first showed clear division into anterior and posterior chambers at $10 \mathrm{~mm}$ TL. Both anterior and posterior swim bladder chambers showed significant $\left(r^{2}\right.$ $=0.69$ and 0.86 for anterior and posterior chambers respectively, $P \ll 0.001$ for both) increases in length over development (Fig. 8). The anterior chamber tended to be more spherical than the posterior, with the posterior becoming more elongate as fish grew.

The first evidence of Weberian ossicle formation was seen at $7 \mathrm{~mm}$ TL [Fig. 9(a)]. At this size, the ossicles were quite small and had large gaps between ossicular elements. By $13 \mathrm{~mm} \mathrm{TL}$, the size of the individual ossicles had increased and the supraoccipital bone first became evident but

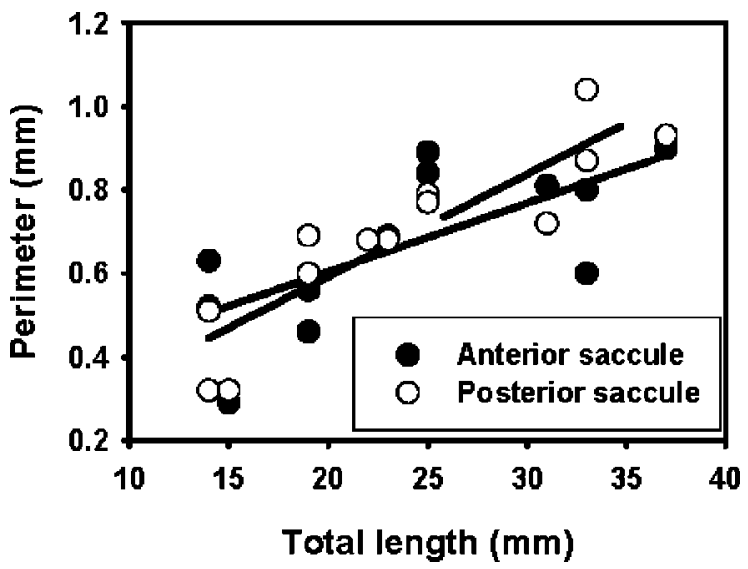

FIG. 7. The perimeter length of the sensory area of the anterior and posterior saccules increased significantly with growth but there was no significant difference in the rate of increase between these two saccular areas.

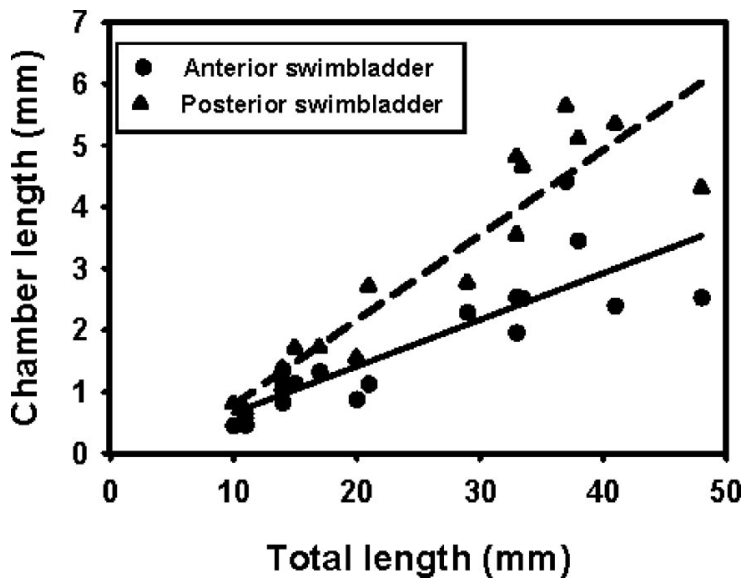

FIG. 8. The length of both the anterior and posterior swim bladder chambers showed significant increases with growth of zebrafish larvae.

there remained large gaps between individual ossicular elements [Fig. 9(b)]. Ossicle size increased but in fish at $17 \mathrm{~mm}$ TL there were still large spaces between individual ossicles and there was a prominent gap between the supraoccipital bone and the supraneurals of the Weberian apparatus [Fig. 9(c)]. By $19.5 \mathrm{~mm}$ TL, the ossicles were well formed and there was no gap between the supraoccipital bone and the supraneural elements of the Weberian apparatus, forming an unbroken chain of ossicles from the swimbladder to the inner ear [Fig. 9(d)].

\section{DISCUSSION}

Before discussing the actual results of any physiological study, it is important to realize the potential limitations on the stimulus delivery and resulting responses. All sound stimuli contain both pressure and displacement information and, in our setup, with the speaker in the water, there is
A

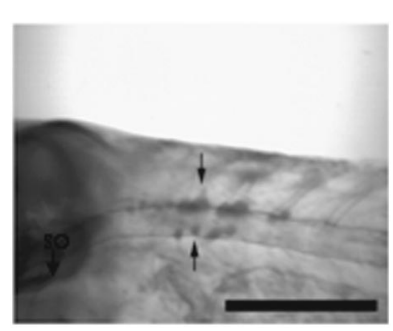

C

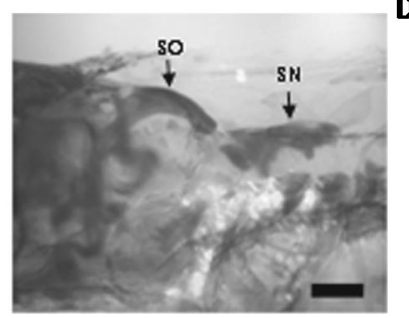

$\mathbf{B}$

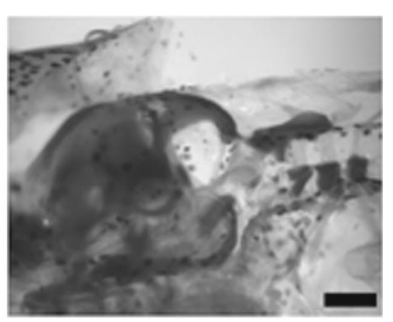

D

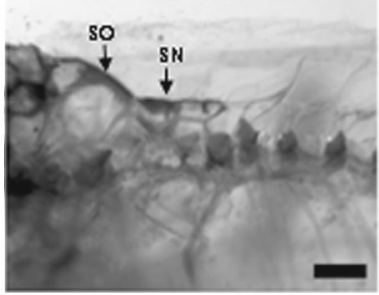

FIG. 9. Weberian ossicles are first evident at $7 \mathrm{~mm}$ total length in zebrafish [arrows in (a)] but are very small and poorly connected. By $13 \mathrm{~mm}$ (b) the ossicles are larger but large gaps remain between individual elements. By 17 mm TL (c) the dorsal plate has expanded but there are still gaps between individual elements and the supraoccipital $(\mathrm{SO})$ is not connected to the supraneural (SN) Weberian elements. By $19.5 \mathrm{~mm}$ TL (d) the supraoccipital bone is well attached to the supraneurals, forming an unbroken chain from the Weberian apparatus to the inner ear. Scale bars $=0.1 \mathrm{~mm}$. 
probably quite a bit of displacement information present at the lowest frequencies used. Since the main purpose of this study was to examine changes in auditory ability between animals under constant experimental conditions, this does not cause a problem in the current study but must be kept in mind.

The differences in waveform shape at all sizes between responses to low $(100-200 \mathrm{~Hz})$ and middle to high (400$4000 \mathrm{~Hz}$ ) frequencies suggest that perhaps different systems may be involved in detection of these frequencies. The fish should be well within the near-field domain for $100-200 \mathrm{~Hz}$ in the current setup (Rogers and Cox, 1988) so the lateral line system could also be stimulated by displacement effects of the presented sound stimuli. The multiple waveforms seen in response to $100-$ and $200-\mathrm{Hz}$ stimuli therefore could represent a combination of lateral line and auditory responses, whereas higher frequencies would be expected to cause less stimulation to the lateral line (Rogers and Cox, 1988). Responses to tone bursts at $400 \mathrm{~Hz}$ and above should consist of mainly auditory contributions. Alternatively, the waveforms in response to 100 - and $200-\mathrm{Hz}$ stimulation might be the frequency doubling seen by Flock (1965), with the higher frequencies just representing temporal integration of the signal. There has as yet been no study published detailing how changes in waveform shape may relate to sensory structures in fish, as has been detailed so well in mammals (Hall, 1992). Analysis of this question may provide valuable insights on pathways of auditory transduction in fishes.

The increase of maximum detectable frequency seen in the current study has not been reported before for fishes, but is similar to data for mammals and birds. The development of the middle ear in mammals and birds allows transmission and therefore detection of higher frequency information in the inner ear (Ehret and Romand, 1981; Saunders et al., 1983; Geal-Dor et al., 1993; Hill et al., 1998). In the current study, development of the Weberian ossicles coincides with expansion of auditory bandwidth. Fish in the $10-13 \mathrm{~mm}$ size class never responded to tone bursts above $200 \mathrm{~Hz}$ and their Weberian ossicles were small with large gaps between individual elements. The 15-16 and $17-20 \mathrm{~mm}$ size classes showed a gradual increase in detectable frequencies coincident with increases in size and connectivity of the Weberian elements and in the size of the swimbladder. By $20 \mathrm{~mm}$ the ossicles formed a continuous chain between a well developed swimbladder and the inner ear and those animals responded to pure tones up to $4000 \mathrm{~Hz}$. In adult fish, it has long been hypothesized that the Weberian apparatus and swimbladder are responsible for transmitting higher frequency auditory information to the inner ear (von Frisch, 1938; Fay and Popper, 1974), and deflation of the swim bladder results in a reduction in high frequency sensitivity in ostariophysans such as zebrafish (Fay and Popper, 1974; Yan et al., 2000). Our results are consistent with these observations. As the ossicles developed and became more highly connected to one another in zebrafish, and as the swim bladder increased in size, we saw a gradual shift in maximum detectable frequency from $200 \mathrm{~Hz}$ up to $4000 \mathrm{~Hz}$. This then suggests that the ossicles and swimbladder are essential for detection of high frequency information in ostariophysan fishes.

It is also possible that the changes we saw in maximum detectable frequency are due to selective addition of high frequency hair cells in the saccule. Fish in the family Cyprinidae (to which zebrafish and goldfish belong) may have some degree of frequency coding in the saccule, such that higher frequencies are detected in the anterior saccule and lower frequencies are detected in the posterior saccule $(\mathrm{Fu}-$ rukawa and Ishii, 1967; Fay, 1978; Moeng and Popper, 1984), although this still remains unclear. If selective addition of higher frequency hair cells were occurring with development, we would have expected to see differential growth of the saccule in the anterior-posterior plane. We did not see this but instead saw both regions growing at the same rate. There are also no differences in density distributions of saccular hair cells in zebrafish over development (Higgs et al., 2002a), so measuring saccular size should be a good indicator of changes in hair cell distributions. Thus the increase in maximum detectable frequency is apparently not explained by selective addition of higher frequency hair cells.

The fact that there was no change in auditory sensitivity is interesting. Previous reports in teleosts have found either no change in auditory sensitivity with growth of adults in hearing specialists (i.e., a species with extra-aural hearing specializations; Popper, 1971; Higgs et al., 2002a), a drastic improvement in sensitivity in a hearing generalist (i.e., a species with no extra-aural hearing specializations; Kenyon, 1996), or small changes over a restricted size range of fish in the two other teleost species tested (Iwashita et al., 1999; Wysocki and Ladich, 2001). In the current study, we saw an increase in the number of auditory hair cells (increase in the number of sensory receptors) but no change in auditory sensitivity, at least not at the level of the ABR.

Measuring the physiological sensitivity of the eighth cranial nerve during development of an elasmobranch (the ray Raja clavata), Corwin (1983) found an increased sensitivity in conjunction with an increase in number of auditory hair cells. That Corwin (1983) found an increase in sensitivity and we did not may be due to a difference in techniques used between his studies and ours, or simply due to the wide disparity in species examined (elasmobranch versus teleost). Moreover, recordings from the eighth cranial nerve measure a different attribute of hearing than the synchrony required for an ABR response (Hall, 1992), so perhaps an increase in sensory receptors causes a different response in these two auditory measures. Alternatively, the response of the auditory system to an increase in hair cell number may be dependent on the auditory specializations in the studied species. Other studies that have found changes in auditory sensitivity with growth in fish have been conducted on hearing generalists (Corwin, 1983; Kenyon, 1996; Iwashita et al., 1999) or on a hearing specialist with a specialization quite different from that seen in zebrafish and goldfish (Wysocki and Ladich, 2001). The form of auditory specializations may influence the developmental pattern of auditory sensitivity, although many more species will need to be examined before this can be determined. 
A word of caution must be issued concerning comparison of absolute threshold values between laboratories, even when using the same species. The thresholds reported here for zebrafish are up 5-30 dB higher than those reported for goldfish by Yan et al. (2000) using ABR, even though our previous work (Higgs et al., 2002a) showed little difference in threshold between goldfish and zebrafish in our setup. Previous work (Popper et al., 1973; Fay, 1978) has shown a 30-50-dB difference in thresholds in goldfish between laboratories, even when similar methods were used. There is currently no standard method for testing hearing in fish and there are even large differences in technique between laboratories using $\mathrm{ABR}$ [e.g., we test fish under water while Yan et al. (2000) tested fish at the surface interface with an airborne speaker]. These methodological differences will make it impossible to perform interspecific comparisons using data from different laboratories. We propose that all laboratories presenting audiograms for a new species also include an audiogram of goldfish tested in the same system to better facilitate interspecific comparisons.

We postulate the following model for the development of hearing in zebrafish, and perhaps other ostariophysan fishes. By $10 \mathrm{~mm}$ TL, the ear appears quite well developed but the Weberian apparatus is not. As the swim bladder and Weberian ossicles develop and improve connections along the apparatus, more high frequency information can be passed along the ossicles to the inner ear. Once auditory information reaches the ear, the ear can process the information in the larvae as well as in the adult. While hair cells continue to be added to the inner ear throughout the life of the fish (Corwin, 1981, 1983; Popper and Hoxter, 1984; Lombarte and Popper, 1994; Higgs et al., 2002a; current study), we suggest that this addition does not improve sensitivity, at least in zebrafish, but instead is used to keep pace with growth of the ear. This is supported by the fact that regional differences in hair cell density are maintained during development (Higgs et al., 2002a) and by the fact that the different saccular regions grow at the same rate (current study). This also fits the predictions of a model that suggests that hair cell addition is necessary for stable hearing thresholds as the distance between the ear and peripheral structures such as the swimbladder increase (Popper et al., 1988; Rogers et al., 1988; Fineran and Hastings, 2000).

If our model of the development of zebrafish hearing is correct, this represents one more example of how similar the fish auditory system is to those of mammals and birds (see Fay and Popper, 2000). Just as mammals and birds seem to need the development of the middle ear for detection of higher frequencies (Ehret and Romand, 1981; Saunders et al., 1983; Geal-Dor et al., 1993), so too do at least zebrafish need development of the Weberian ossicles to transmit higher frequency information to the inner ear for detection. While it was initially thought that fish could not even hear (von Frisch, 1938), it is becoming increasingly obvious that the auditory system of many species of fish is quite advanced and possesses many of the attributes seen in amniotes (e.g., Fay and Popper, 2000). Fish can contain several types of auditory hair cells (Chang et al., 1992; Popper et al., 1993; Lanford et al., 2000), have sharply tuned auditory fil- ters (e.g., Fay, 1978), can detect sound direction and may be able to localize sounds (e.g., Schuijf and Buwalda, 1975; Hawkins and Sand, 1977; Lu and Popper, 2001), and can also perform complex auditory stream segregation necessary for auditory scene analysis (Fay, 2000). Thus rather than thinking of "the fish" auditory system as a rather general and unspecialized vertebrate ear, it is better to realize that the auditory systems of all vertebrates have many aspects in common and that examination of processes in the ear of a variety of fish species can tell us much about the evolution of the vertebrate auditory system in general (Fay and Popper, 2000).

\section{ACKNOWLEDGMENTS}

We thank Kirsten Poling, Beth Brittan-Powell, and Olivia Haine for critical review of the manuscript and discussions of the data in this study. We would also like to thank Alison Krupin, Sonya Rosenfeld, and Justina Efobi for assistance with the zebrafish developmental morphology. The manuscript was further improved by the comments of two anonymous reviewers. This work was funded as a grant from the NIH-NIDCD No. (DC04502-01) to DMH. Additional support was provided by grants to ANP (NIH-NIDCD No. DC-039036 and NIH-NIA No. AG-015681) and a NIDCD training grant (No. DC-00046).

Bang, P. I., Sewell, W. F., and Malicki, J. J. (2001). "Morphology and cell type heterogeneities of the inner ear epithelia in adult and juvenile zebrafish (Danio rerio)," J. Comp. Neurol. 438, 173-190.

Blaxter, J. H. S., and Batty, R. S. (1985). "The development of startle responses in herring larvae," J. Mar. Biol. Assoc. U.K. 65, 737-750.

Boatwright-Horowitz, S. S., and Megela Simmons, A. (1995). "Postmetamorphic changes in auditory sensitivity of the bullfrog midbrain," J. Comp. Physiol., A 177, 577-590.

Boatwright-Horowitz, S. S., and Megela Simmons, A. (1997). "Transient 'deafness' accompanies auditory development during metamorphosis from tadpole to frog," Proc. Natl. Acad. Sci. U.S.A. 94, 14877-14882.

Brittan-Powell, E. F., and Dooling, R. J. (2000). "Development of auditory sensitivity in budgerigars," J. Acoust. Soc. Am. 107, 2785.

Chang, J. S. Y., Popper, A. N., and Saidel, W. M. (1992). "Heterogeneity of sensory hair cells in a fish ear," J. Comp. Neurol. 324, 621-640.

Corwin, J. T. (1981). "Postembryonic production and aging of inner ear hair cells in sharks," J. Comp. Neurol. 201, 541-553.

Corwin, J. T. (1983). "Postembryonic growth of the macula neglecta auditory detector in the ray, Raja clavata: continual increases in hair cell number, neural convergence, and physiological sensitivity," J. Comp. Neurol. 217, 345-356.

Corwin, J. T., Bullock, T. H., and Schweitzer, J. (1982). "The auditory brain stem response in five vertebrate classes," Electroencephalogr. Clin. Neurophysiol. 54, 629-641.

Dingerkus, G., and Uhler, L. D. (1977). "Enzyme clearing of alcian blue stained whole small vertebrates for demonstration of cartilage," Stain Technol. 52, 229-232.

Dmitrieva, L. P., and Gottlieb, G. (1992). "Development of brainstem auditory pathway in mallard duck embryos and hatchlings," J. Comp. Physiol., A 171, 665-671.

Ehret, G., and Romand, R. (1981). "Postnatal development of absolute auditory thresholds in kittens," J. Comp. Physiol. Psychol. 95, 304-311.

Fay, R. (1978). "Coding of information in single auditory-nerve fibers of the goldfish," J. Acoust. Soc. Am. 63, 136-146.

Fay, R. R. (2000). "Spectral contrasts underlying auditory stream segregation in goldfish (Carassius auratus)," JARO 01, 120-128.

Fay, R. R., and Popper, A. N. (1974). "Acoustic stimulation of the ear of the goldfish (Carassius auratus)," J. Exp. Biol. 61, 243-260.

Fay, R. R., and Popper, A. N. (2000). "Evolution of hearing in vertebrates: the inner ears and processing," Hear. Res. 149, 1-10. 
Fineran, J. J., and Hastings, M. C. (2000). "A mathematical analysis of the peripheral auditory system mechanics in the goldfish (Carassius auratus)," J. Acoust. Soc. Am. 108, 1308-1321.

Flock, A. (1965). "Electron microscopic and electrophysiological studies on the lateral line canal organ," Acta Oto-Laryngol., Suppl. 199, 1-90.

Fuiman, L. A., Poling, K. R., and Higgs, D. M. (1998). "Quantifying developmental progress for comparative studies of larval fishes," Copeia 1998, 602-611.

Fuiman, L. A., Smith, M. E., and Malley, V. N. (1999). "Ontogeny of routine swimming speed and startle responses in red drum, with a comparison of responses to acoustic and visual stimuli," J. Fish Biol. 55, 215-226.

Furukawa, T., and Ishii, Y. (1967). "Neurophysiological studies on hearing in goldfish," J. Neurophysiol. 30, 1377-1403.

Geal-Dor, M., Freeman, S., Li, G., and Sohmer, H. (1993). "Development of hearing in neonatal rats: air and bone conducted ABR thresholds," Hear. Res. 69, 236-242.

Grande, T., and Young, B. (Submitted). "Ontogeny of the Weberian apparatus in the zebrafish Danio rerio (Ostariophysi, Cypriniformes)," Can J. Zool.

Gray, L. (1993). "Developmental changes in chickens' masked thresholds," Dev. Psychobiol. 26, 447-457.

Gray, L., and Rubel, E. W. (1985). "Development of absolute thresholds in chickens," J. Acoust. Soc. Am. 77, 1162-1172.

Haddon, C., and Lewis, J. (1996). "Early ear development in the embryo of the zebrafish, Danio rerio," J. Comp. Neurol. 365, 113-128.

Hall, J. W. (1992). Handbook of Auditory Evoked Responses (Allyn and Bacon, Boston).

Hawkins, A. D., and Sand, O. (1977). "Directional hearing in the median vertical plane by the cod," J. Comp. Physiol. [A] 122, 1-8.

Higgs, D. M., Souza, M. J., Wilkins, H. R., Presson, J. C., and Popper, A. N. (2002a). "Age- and size-related changes in the inner ear and hearing ability of the adult zebrafish (Danio rerio)," JARO 3, 174-184.

Higgs, D. M., Souza, M. J., Wilkins, H. R., Presson, J. C., and Popper, A. N. (2002b). "Age- and size-related changes in the inner ear and hearing ability of the adult zebrafish (Danio rerio) ERRATUM," JARO 3, 222.

Hill, K. G., Cone-Wesson, B., and Liu, G.-B. (1998). "Development of auditory function in the tammar wallaby Macropus eugenii," Hear. Res. 117, 97-106.

Iwashita, A., Sakamoto, M., Kojima, T., Watanabe, Y., and Soeda, H. (1999). "Growth effects on the auditory threshold of Red Sea bream," Nippon Suisan Gakkaishi 65, 833-838.

Kenyon, T. N. (1996). "Ontogenetic changes in the auditory sensitivity of damselfishes (Pomacentridae)," J. Comp. Physiol., A 179, 553-561.

Kenyon, T. N., Ladich, F., and Yan, H. Y. (1998). "A comparative study of hearing ability in fishes: the auditory brainstem response approach," $\mathrm{J}$. Comp. Physiol. 182, 307-318.

Klein, A. J. (1984). "Frequency and age-dependent auditory evoked potential thresholds in infants," Hear. Res. 16, 291-297.

Kuse, H., and Okaniwa, A. (1993). "Postnatal development of the auditory brainstem response (ABR) in beagles," Exp. Anim. 42, 377-382.

Lanford, P. J., Platt, C., and Popper, A. N. (2000). "Structure and function in the saccule of the goldfish (Carassius auratus): a model of diversity in the non-amniote ear," Hear. Res. 143, 1-13.

Lombarte, A., and Popper, A. N. (1994). "Quantitative analyses of postembryonic hair cell addition in the otolithic endorgans of the inner ear of the European hake, Merluccius merluccius (Gadiformes, Teleostei)," J. Comp. Neurol. 345, 419-428.

Lu, Z., and Popper, A. N. (2001). "Neural response directionality correlates of hair cell orientation in a teleost fish," J. Comp. Physiol., A 187, 453465.

Mann, D., Higgs, D., Tavolga, W., Souza, M., and Popper, A. N. (2001). "Ultrasound detection by clupeiform fishes," J. Acoust. Soc. Am. 109, $3048-3054$.

Moeng, R., and Popper, A. N. (1984). "Auditory responses of saccular neurons of the catfish, Ictalurus punctatus," J. Comp. Physiol. 155, 615-624.

Moore, D. R., and Irvine, I. F. (1979). "The development of some peripheral and central auditory responses in the neonatal cat," Brain Res. 163, 4959 .
Platt, C. (1977). "Hair cell distribution and orientation in goldfish otolith organs," J. Comp. Neurol. 172, 283-298.

Platt, C. (1993). "Zebrafish inner ear sensory surfaces are similar to those in goldfish," Hear. Res. 65, 133-140.

Popper, A. N. (1971). "The effects of fish size on auditory capacities of the goldfish,” J. Aud Res. XI, 239-247.

Popper, A. N., and Hoxter, B. (1984). "Growth of a fish ear: 1. Quantitative analysis of hair cell and ganglion cell proliferation," Hear. Res. 15, 133142.

Popper, A. N., Chan, A. T. H., and Clarke, N. L. (1973). "An evaluation of methods for behavioral investigations of teleost audition," Behav. Res. Methods Instrum. 5, 470-472.

Popper, A. N., Saidel, W. M., and Chang, J. S. Y. (1993). "Two types of sensory hair cell in the saccule of a teleost fish," Hear. Res. 64, 211-216.

Popper A. N., Rogers P. H., Saidel W. M., and Cox, M. (1988). "The role of the fish ear in sound processing," in Sensory Biology of Aquatic Animals, edited by J. Atema, R. R. Fay, A. N. Popper, and W. N. Tavolga (SpringerVerlag, New York), pp. 687-710.

Pujol, R., and Marty, R. (1970). "Postnatal maturation in the cochlea of the cat," J. Comp. Neurol. 139, 115-126.

Riley, B. B., Zhu, C., Janetopoulos, C., and Aufderheide, K. J. (1997). “A critical period of ear development controlled by distinct populations of ciliated cells in the zebrafish," Dev. Biol. 191, 191-201.

Rogers, P. H., and Cox, M. (1988). "Underwater sound as a biological stimulus," in Sensory Biology of Aquatic Animals, edited by J. Atema, R. R. Fay, A. N. Popper, and W. N. Tavolga (Springer-Verlag, New York), pp. $131-150$.

Rogers, P. H., Popper, A. N., Cox, M., and Saidel, W. M. (1988). "Processing of acoustic signals in the auditory system of bony fish," J. Acoust. Soc. Am. 83, 338-349.

Rubel, E. W. (1978). "Ontogeny of structure and function in the vertebrate auditory system," in Handbook of Sensory Physiology Vol. IX, edited by M. Jacobson (Springer-Verlag, New York), pp. 135-237.

Saunders, J. C., Relkin, E. M., Rosowski, J. J., and Bahl, C. (1983). "Changes in middle-ear input admittance during postnatal auditory development in chicks," Hear. Res. 24, 227-235.

Schofner, W. P., and Feng, A. S. (1981). "Post-metamorphic development of the frequency selectivities and sensitivities of the peripheral auditory system of the bullfrog Rana catesbiana," J. Neurophysiol. 93, 181-196.

Schuijf, A., and Buwalda, R. J. A. (1975). "On the mechanism of directional hearing in cod (Gadus morhua L.)," J. Comp. Physiol. 98, 333-343.

von Frisch, K. (1938). "The sense of hearing in fish," Nature (London) 141, $8-11$.

Walsh, E. J., McGee, J., and Javel, E. (1986a). "Development of auditoryevoked potentials in the cat. I. Onset of response and development of sensitivity," J. Acoust. Soc. Am. 79, 712-724.

Walsh, E. J., McGee, J., and Javel, E. (1986b). "Development of auditoryevoked potentials in the cat. II. Wave latencies," J. Acoust. Soc. Am. 79, 725-744.

Walsh, E. J., McGee, J., and Javel, E. (1986c). "Development of auditoryevoked potentials in the cat. III. Wave amplitudes," J. Acoust. Soc. Am. 79, 745-754.

Waterman, R. E., and Bell, D. H. (1984). "Epithelial fusion during early semicircular canal formation in the embryonic zebrafish, Danio rerio," Anat. Rec. 210, 101-114.

Werner, L. A., and Gray, L. (1998). "Behavioral studies of hearing development," in Development of the Auditory System, edited by E. W. Rubel, A. N. Popper, and R. R. Fay (Springer-Verlag, New York), pp. 12-79.

Wysocki, L. E., and Ladich, F. (2001). "The ontogenetic development of auditory sensitivity, vocalization and acoustic communication in the labyrinth fish Trichopsis vittata," J. Comp. Physiol., A 187, 177-187.

Yan, H. Y., and Curtsinger, W. S. (2000). "The otic gasbladder as an ancillary auditory structure in a mormyrid fish," J. Comp. Physiol., A 186, 595-602.

Yan, H. Y., Fine, M. L., Horn, N. S., and Colón, W. E. (2000). "Variability in the role of the gasbladder in fish audition," J. Comp. Physiol., A 186, 435-445.

Zar, J. H. (1984). Biostatistical Analysis, 2nd ed. (Prentice-Hall, Englewood Cliffs, NJ). 